\title{
Hubungan Pengetahuan, Sikap Dan Pemahaman Agama Islam Terhadap Perilaku Hidup Bersih Dan Sehat (PHBS)
}

\section{The Relations Between Knowledge, Attitude, and Understanding of Islamic Religion and The Behavior Clean and Healthy Living (PHBS)}

\author{
Ana Utami Zainal ${ }^{(1)}$, Nia Musniati(1) \\ ${ }^{(1)}$ Program Studi Kesehatan Masyarakat, Fakultas Ilmu-Ilmu Kesehatan \\ Universitas Muhammadiyah Prof.Dr. Hamka Jakarta
}
Korespondensi Penulis: Ana Utami Zainal, Program Studi Kesehatan Masyarakat Fakultas Ilmu-Ilmu Kesehatan, Universitas Muhammadiyah Prof. DR. Hamka
Email: anautamizainal@uhamka.ac.id

\begin{abstract}
ABSTRAK
Proporsi rumah tangga yang tidak melakukan PHBS di Indonesia tahun 2013 adalah 67,7\% (Kementerian Kesehatan Republik Indonesia, 2013). Proporsi rumah tangga tidak melakukan PHBS di DKI Jakarta tahun 2017 adalah 42,9 \% (Dinas Kesehatan Provinsi DKI Jakarta, 2018). Selain itu, belum terdapat data PHBS mahasiswa FIKES UHAMKA karena belum adanya penelitian terdahulu. Tujuan penelitian ini adalah mengetahui hubungan pengetahuan, sikap, dan pemahaman Agama Islam terhadap PHBS mahasiswa FIKES UHAMKA. Jenis penelitian yang digunakan adalah penelitian survei analitik dengan desain penelitian cross sectional. Populasi pada penelitian ini adalah seluruh mahasiswa Program studi kesehatan masyarakat FIKES UHAMKA. Pengambilan sampel dengan menggunakan proporsional random sampling dengan jumlah sampel 138 orang. Hasil analisis univariat menunjukkan bahwa sebagian besar responden memiliki PHBS yang kurang baik (57,2\%), pengetahuan yang baik (50,7\%), sikap yang baik (60,1\%), dan pemahaman Agama Islam yang baik (70,3\%). Hasil bivariat menunjukkan tidak ada hubungan yang bermakna antara pengetahuan, sikap, dan pemahaman Agama Islam dengan PHBS ( $P$ value $>0,05)$. Saran dari penelitian ini, untuk FIKES UHAMKA, diharapkan adanya kegiatan yang berkelanjutan terkait dengan pelaksanaan PHBS agar mahasiswa tidak hanya sekedar mengetahui tetapi juga melakukan tindakan PHBS. Selain itu diperlukan adanya dukungan melalui fasilitas penunjang PHBS.
\end{abstract}

Kata kunci: PHBS, Pengetahuan, Sikap, Pemahaman Agama Islam

\section{ABSTRACT}

The proportion of households that did not carry out PHBS in Indonesia in 2013 was $67.7 \%$ (Ministry of Health of the Republic of Indonesia, 2013). The proportion of households not doing PHBS in DKI Jakarta in 2017 was 42.9\% (DKI Jakarta Provincial Health Office, 2018). Also, there is no PHBS data for UHAMKA FIKES students because there has been no previous research. This study aimed to determine the relationship between knowledge, attitudes, and understanding of Islam towards the PHBS of UHAMKA FIKES students. This type of research is analytical survey research with a cross-sectional research design. The population in this study were all students of the Public Health Study Program, FIKES UHAMKA. Sampling using proportional random sampling with a sample size of 138 people. The results of the univariate analysis showed that most of the respondents had poor PHBS (57.2\%) and good knowledge (50, 7\%), a good attitude (60.1\%), and a good understanding of Islam (70.3\%). The bivariate results showed no significant relationship between knowledge, attitudes, and understanding of Islam and PHBS (P value> 0.05). Suggestions from this research, for UHAMKA FIKES, it is hoped that there will be continuous activities related to the implementation of PHBS so that students do not only know but also take PHBS actions. Apart from that, support is needed through PHBS supporting facilities.

Keywords: PHBS, Knowledge, Attitude, Understanding of Islam 


\section{PENDAHULUAN}

Proporsi rumah tangga yang tidak melakukan PHBS di Indonesia tahun 2013 adalah 67,7\% (Kementerian Kesehatan Republik Indonesia, 2013). Proporsi rumah tangga tidak melakukan PHBS di DKI Jakarta tahun 2017 adalah 42,9 \% (Dinas Kesehatan Provinsi DKI Jakarta, 2018).

Islam sangat mengutamakan kebersihan. Dimana kebersihan harus dijaga oleh setiap manusia mulai dari diri sendiri sampai lingkungan sekitarnya. Salah satu keutamaan kebersihan dalam Islam adalah terhindar dari penyakit (Sumantri, 2015). Hal ini dijelaskan dalam Hadist, "Miftaahush sholaati thohaarrotu laa tuqbalu sholaatun bighoiri thohuurin" yang artinya Kunci sholat adalah suci, tidak diterima sholat apabila tidak suci (HR Abu Dawud). Shalat merupakan tiang agama, umat islam wajib melaksanakan shalat 5 waktu dalam sehari semalam sehingga umat islam dianjurkan untuk selalu menjaga kebersihan dan kesucian, misalnya dengan berwudhu, mandi dan membersikan pakaian. Menurut Al Quran Al Mudatsir ayat 3, "Wa syiabaka fathohhir" : (dan pakaianmu bersihkanlah). Tidak hanya kebersihan diri, Allah SWT juga memerintahkan untuk menjaga lingkungan itu tertuang dalam Al Quran Surat Arrum ayat 41, surat Al Baqoroh ayat 222.

Pendidikan Agama Islam dan

Kemuhammadiyaan merupakan mata kuliah unggulan bagi mahasiswa di lingkup kampus Muhammadiyah termasuk Universitas Prof. DR. HAMKA (UHAMKA). Oleh karena itu, mahasiswa diharapkan lebih unggul dalam memahami pengetahuan agama Islam dan Kemuhammadiyaan. Pengetahuan dan pemahaman terhadap nilai-nilai Islam tersebut juga akan berdampak pada perilaku sehari-hari. Pengetahuan atau pemahaman seseorang adalah domain penting untuk membentuk perilakunya (Notoatmodjo, 2007).

Perilaku Hidup Bersih dan Sehat (PHBS) mengenai perilaku seseorang menyangkut kebersihan yang dapat mempengaruhi kesehatannya. Hasil studi pendahuluan yang dilakukan pada 10 mahasiswa FIKES didapatkan bahwa 6 mahasiswa (60\%) memiliki perilaku PHBS yang kurang baik. Studi pendahuluan ini dilakukan untuk menggali masalah penelitian. Dari hasil pengamatan ditemukan masih banyak sampah yang berserakan, toilet yang kurang bersih, tempat cuci tangan yang belum tersedia di beberapa tempat serta tidak tersedianya sabun untuk mencuci tangan. Selain itu, belum terdapat data PHBS mahasiswa FIKES UHAMKA karena belum adanya penelitian terdahulu. Tujuan penelitian ini adalah mengetahui hubungan tingkat pengetahuan, sikap, dan pemahaman Agama Islam terhadap PHBS mahasiswa Prodi Kesehatan Masyarakat FIKES UHAMKA.

\section{SUBYEK DAN METODE}

Penelitian ini merupakan survei analitik. Desain yang digunakan pada penelitian ini adalah cross-sectional (potong lintang) dimana pengukuran variabel dependen dan independen dilakukan secara bersamaan. Variabel dependen pada penelitian ini adalah PHBS dan variabel independennya adalah pengetahuan, sikap dan pemahaman Agama Islam. Penelitian dilaksanakan di Kampus UHAMKA Limau pada bulan Agustus - Februari 2019.

Populasi dalam penelitian ini adalah seluruh mahasiswa Prodi Kesmas Angkatan 2015-2017 FIKES UHAMKA. Berdasarkan perhitungan sampel minimal, jumlah sampel dalam penelitian ini adalah 138 orang dengan menggunakan proporsional random sampling sebagai teknik pengambilan sampel. Kriteria inklusi pada penelitian ini adalah responden merupakan mahasiswa dan mahasiswi yang telah lulus mata kuliah ibadah dan akhlak. Pokok bahasan dalam mata kuliah tersebut adalah thaharah yang menjelaskan tentang konsep kesucian atau kebersihan.

Variabel yang diteliti pada penelitian ini adalah variabel PHBS, pengetahuan, sikap dan pemahaman agama Islam. Variabel PHBS mengukur perilaku hidup bersih dan sehat diantaranya mencuci tangan dengan sabun dan air mengalir, menjaga kebersihan diri dan lingkungan kampus, mengonsumsi makanan/jajanan sehat, mengonsumsi buah dan sayur, memanfaatkan toilet kampus untuk BAB/BAK, memberantas jentik nyamuk di kampus, membuang sampah pada tempatnya, beraktivitas fisik secara teratur 30 menit dalam sehari, perilaku merokok, dan perilaku menimbang berat badan dan mengukur tinggi badan setiap bulan. Variabel pengetahuan mengukur pengetahuan tentang PHBS, variabel sikap mengukur sikap tentang PHBS, dan pemahaman agama Islam mengukur pemahaman agama Islam tentang PHBS.

Pengumpulan data varibel PHBS, pengetahuan, sikap dan pemahaman agama 
Islam pada penelitian ini menggunakan data primer. Data primer dikumpulkan dengan menggunakan alat ukur berbentuk kuesioner yang diberikan kepada sampel penelitian serta disetujui dan diisi sendiri oleh responden secara langsung. Kuesioner terdiri dari 5 bagian yaitu kuesioner identitas responden, berisi tentang nama, jenis kelamin, umur dan tahun angkatan diterima di UHAMKA, kueisoner bagian I, berisi 20 pertanyaan pengetahuan tentang PHBS yaitu indikator PHBS di kampus, kuesioner bagian II, berisi 17 pertanyaan sikap PHBS dengan bentuk checklist jawaban yaitu: sangat setuju, setuju, ragu-ragu, tidak setuju, dan sangat tidak setuju, kuesioner bagian III berisi 12 pertanyaan tentang perilaku PHBS dengan bentuk checklist jawaban yaitu : ya, kadang-kadang, dan tidak, dan kuesioner bagian IV berisi 7 pertanyaan pemahaman agama Islam dengan 3 pilihan jawaban

Skoring pada pertanyaan pengetahuan dan pemahaman agama Islam, jika responden menjawab benar diberikan skor 1, jika responden menjawab salah diberikan skor 0 . Skoring untuk pernyataan sikap positif, skor 5 jika responden menjawab sangat setuju (SS), skor 4 jika responden menjawab setuju (S), skor 3 jika responden menjawab ragu (R), skor 2 jika responden menjawab tidak setuju (TS), dan skor 1 jika responden menjawab sangat tidak setuju (STS). Skoring untuk pernyataan sikap negatif, skor 1 jika responden menjawab sangat setuju (SS), skor 2 jika responden menjawab setuju (S), skor 3 jika responden menjawab ragu (R), skor 4 jika responden menjawab tidak setuju (TS) dan skor 5 jika responden menjawab sangat tidak setuju (STS). Skoring pada pertanyaan perilaku tentang PHBS, jika responden menjawab ya diberi skor 2 , kadangkadang diberi skor 1 dan tidak diberi skor 0 . Pengolahan dan analisis data menggunakan software statistik. Analisis data pada penelitian ini adalah analisis univariat dan analisis bivariat. Analisis bivariat menggunakan uji Chi-square dengan $\alpha=5 \%$.

HASIL

Tabel 1. Nilai Statistik dan Hasil Uji Kolmogorof Smirnov

\begin{tabular}{llllllll}
\hline Total skor & Mean & Median & Modus & Min & Maks & SD & $\begin{array}{l}\text { P } \\
\text { value }\end{array}$ \\
\hline PHBS & 16,14 & 16,00 & 16 & 10 & 22 & 2,243 & 0,097 \\
Pengetahuan & 45,59 & 43,00 & 27 & 23 & 73 & 17,50 & 0,001 \\
Sikap & 75,62 & 76,00 & 76 & 61 & 84 & 5,040 & 0,017 \\
Pemahaman agama & 11,14 & 11,00 & 11 & 6 & 14 & 1,587 & 0,001 \\
Islam & & & & & & & \\
\hline
\end{tabular}

Tabel 2. Distribusi Frekuensi Berdasarkan PHBS, Pengetahuan, Sikap dan Pemahaman Agama Islam

\begin{tabular}{lcc}
\hline Variabel & n & \% \\
\hline PHBS & 59 & 42,8 \\
$\quad$ Baik & 79 & 57,2 \\
$\quad$ Kurang Baik & & \\
Pengetahuan & 70 & 50,7 \\
$\quad$ Baik & 68 & 49,3 \\
$\quad$ Kurang Baik & & \\
Sikap & 83 & 60,1 \\
$\quad$ Baik & 55 & 39,9 \\
$\quad$ Kurang Baik & & \\
Pemahaman Agama Islam & 97 & 70,3 \\
$\quad$ Baik & 41 & 29,7 \\
$\quad$ Kurang Baik & &
\end{tabular}


Tabel 1 menunjukkan rata-rata total skor PHBS adalah 16,14 dengan nilai total skor terendah 10 dan nilai total skor tertinggi 22 . Hasil uji Kolmogorof Smirnov menunjukkan data total skor PHBS memiliki distribusi normal ( $P$ value 0,097 ). Rata-rata total skor pengetahuan tentang PHBS adalah 45,59 dengan nilai total skor terendah 23 dan nilai total skor tertinggi 73. Hasil uji Kolmogorof Smirnov menunjukkan data total skor pengetahuan tentang PHBS memiliki distribusi tidak normal ( $P$ value 0,001$)$. Rata-rata total skor sikap tentang PHBS adalah 75,62 dengan nilai total skor terendah 61 dan nilai total skor tertinggi 84. Hasil uji Kolmogorof Smirnov menunjukkan data total skor sikap tentang PHBS memiliki distribusi tidak normal ( $P$ value 0,017). Rata-rata total skor pemahaman Agama Islam adalah 11,14 dengan nilai total skor terendah 6 dan nilai total skor tertinggi 14 .
Hasil uji Kolmogorof Smirnov menunjukkan data total skor pemahaman Agama Islam memiliki distribusi tidak normal ( $P$ value 0,001).

Selanjutnya variabel PHBS dikategorikan menjadi baik jika > mean $(16,14)$, kurang baik jika $\leq$ mean $(16,14)$. Variabel pengetahuan dikategorikan menjadi baik jika $>$ median $(43,00)$, kurang baik jika $\leq$ median $(43,00)$. Variabel sikap dikategorikan menjadi baik jika > median $(76,00)$, kurang baik jika $\leq$ median $(76,00)$. Variabel pemahaman agama Islam dikategorikan menjadi baik jika > median $(11,00)$, kurang baik jika $\leq$ median $(11,00)$.

Tabel 2 menunjukkan bahwa sebagian besar responden memiliki PHBS yang kurang baik $(57,2 \%)$, pengetahuan yang baik $(50,7 \%)$, sikap yang baik $(60,1 \%)$, dan pemahaman Agama Islam yang baik (70,3\%).

Tabel 3. Hubungan Pengetahuan, Sikap, Pemahaman Agama Islam dengan PHBS

\begin{tabular}{|c|c|c|c|c|c|c|c|c|}
\hline \multirow{3}{*}{ Variabel } & \multicolumn{4}{|c|}{ PHBS } & \multicolumn{2}{|c|}{ Total } & \multirow{3}{*}{$\begin{array}{c}P \\
\text { value }\end{array}$} & \multirow{3}{*}{$\begin{array}{c}\text { PR } \\
(95 \% \mathrm{CI})\end{array}$} \\
\hline & \multicolumn{2}{|c|}{ Baik } & \multicolumn{2}{|c|}{$\begin{array}{c}\text { Kurang } \\
\text { Baik }\end{array}$} & \multirow[b]{2}{*}{$\mathbf{N}$} & \multirow[b]{2}{*}{$\%$} & & \\
\hline & $\mathbf{n}$ & $\%$ & n & $\%$ & & & & \\
\hline \multicolumn{9}{|l|}{ Pengetahuan } \\
\hline Baik & 28 & 40,0 & 42 & 60,0 & 70 & 100 & \multirow[t]{2}{*}{0,623} & 0,877 \\
\hline Kurang Baik & 31 & 45,6 & 37 & 54,4 & 68 & 100 & & $\begin{array}{c}(0,596- \\
1,292)\end{array}$ \\
\hline \multicolumn{9}{|l|}{ Sikap } \\
\hline Baik & 41 & 49,4 & 42 & 50,6 & 83 & 100 & \multirow[t]{2}{*}{0,078} & 1,509 \\
\hline Kurang Baik & 18 & 32,7 & 37 & 67,3 & 55 & 100 & & $\begin{array}{l}(0,975- \\
2,337)\end{array}$ \\
\hline \multicolumn{9}{|c|}{$\begin{array}{l}\text { Pemahaman Agama } \\
\text { Islam }\end{array}$} \\
\hline Baik & 39 & 40,2 & 58 & 59,8 & 97 & 100 & \multirow[t]{2}{*}{0,458} & 0,824 \\
\hline Kurang Baik & 20 & 48,8 & 21 & 51,2 & 41 & 100 & & $\begin{array}{c}(0,554- \\
1,225)\end{array}$ \\
\hline
\end{tabular}

Tabel 3 menunjukkan tidak ada hubungan yang bermakna antara PHBS dengan pengetahuan $(P$ value 0,623$)$, sikap ( $P$ value $0,078)$, dan pemahaman Agama Islam $(P$ value $0,458)$.

\section{DISKUSI}

Keterbatasan pada penelitian ini adalah pengisian kuesioner yang diisi sendiri oleh responden sehingga terkadang responden tidak memahami butir pertanyaan dan menjawab tidak sesuai dengan keadaan sesungguhnya.
Perilaku merupakan kebiasaan yang melekat pada diri seseorang. PHBS merupakan perilaku yang merupakan kebiasaan yang diharapkan dapat diterapkan dimana saja dan kapan saja termasuk di lingkungan kampus (Adliyani, 2015). PHBS dapat meningkatkan derajat kesehatan masyarakat, dimana masyarakat diharapkan sadar, mau dan mampu melakukan PHBS dalam kehidupan sehari-hari (Adri, 2013).

PHBS terdiri dari PHBS di rumah tangga, PHBS di sekolah, PHBS di tempat kerja, PHBS di sarana kesehatan dan PHBS 
tempat umum. PHBS di lingkungan pendidikan atau sekolah dapat melahirkan lingkungan pendidikan yang ber-PHBS. Indikator PHBS di sekolah adalah cuci tangan pakai sabun dan air mengalir, menggunakan jamban yang bersih dan sehat, mengkonsumsi jajanan sehat, olahraga teratur dan terukur, tidak merokok di sekolah, memberantas jentik nyamuk, membuang sampah pada tempatnya, menimbang berat badan dan tinggi badan setiap bulan (Kemenkes RI, 2011).

Hasil univariat menunjukkan sebagian besar responden memiliki pengetahuan tentang PHBS yang baik (50,7\%). Hal ini karena responden merupakan mahasiswa Fakultas Ilmu-Ilmu Kesehatan yang mendapatkan pembelajaran tentang PHBS. Hasil bivariat didapatkan bahwa tidak ada hubungan yang signifikan antara pengetahuan dengan PHBS $(P$ value 0,623). Hasil penelitian Muliadi (2015) juga menunjukkan tidak ada hubungan yang signifikan antara Pengetahuan dengan PHBS $(P$ value 0,405) (Muliadi, 2015). Namun penelitian ini berbeda dengan hasil penelitian Chandra (2017) yang menunjukkan ada hubungan yang signifikan antara pengetahuan dengan PHBS ( $P$ value 0,029).

Salah satu fakor yang mempengaruhi pengetahuan adalah sumber informasi. Sumber informasi tersebut dapat diperoleh dari berbagai media, dokumen resmi, dan informasi dari tenaga kesehatan (Notoatmodjo, 2012). Pengetahuan atau pemahaman seseorang adalah domain penting untuk membentuk perilakunya (Notoatmodjo, 2007).

Tabel 2 menunjukkan responden sebagian besar memiliki sikap yang baik $(60,1 \%)$. Hasil bivariat didapatkan bahwa tidak ada hubungan yang signifikan antara sikap dengan PHBS ( $P$ value 0,078 ). Hasil penelitian Seni (2010) juga menunjukkan tidak ada hubungan yang signifikan antara sikap dengan PHBS ( $P$ value 1,000) (Seni, 2015). Namun penelitian ini berbeda dengan hasil penelitian Bawole (2018) yang menunjukkan ada hubungan yang signifikan antara sikap dengan PHBS ( $P$ value 0,021$)$. Hasil penelitian Haerani (2011) juga menunjukkan ada hubungan yang bermakna antara sikap dengan penerapan PHBS, semakin baik sikap responden maka akan baik pula penerapan PHBS $(P$ value 0,003). Sikap merupakan salah satu faktor predisposisi dari perilaku (Green, 2005). Notoatmodjo (2007) menyatakan bahwa sikap adalah respon seseorang terhadap sebuah stimulus/objek yang masih tertutup (Notoatmodjo, 2007). Agama merupakan faktor penting terbentukanya sikap, diantaranya agama mengajarkan kepengikutnya tentang apa yang benar atau salah, apa yang diperintahkan dan apa yang dilarang (Notoatmodjo, 2007 dan Azwar, 2005).

Hasil univariat menunjukkan bahwa responden memiliki pemahaman agama Islam yang baik tentang PHBS (70,3\%). Pendidikan Agama Islam dan Kemuhammadiyaan merupakan mata kuliah unggulan bagi mahasiswa di lingkup kampus Muhammadiyah termasuk Universitas Prof. DR. HAMKA (UHAMKA). Oleh karena itu, mahasiswa diharapkan lebih unggul dalam memahami pengetahuan agama Islam dan Kemuhammadiyaan. Pengetahuan dan pemahaman terhadap nilai-nilai Islam tersebut juga akan berdampak pada perilaku sehari-hari. Penelitian yang dilakukan oleh Rohman (2017) didapatkan hasil penelitian bahwa ajaran agama tentang kebersihan telah diberikan di lingkungan Pesantren Fadlun Minalloh Wonokromo Pleret Bantul.

Hasil bivariat didapatkan bahwa tidak ada hubungan yang signifikan antara pemahaman agama Islam dengan PHBS $(P$ value 0,458). Hasil penelitian Santoso (2019) juga menunjukkan tidak ada hubungan yang signifikan antara pemahaman agama terhadap PHBS ( $P$ value 0,238). Pengetahuan dengan PHBS ( $P$ value 0,405) (Muliadi, 2015). Namun penelitian ini berbeda dengan hasil penelitian Haerani (2011) yang menunjukkan ada hubungan yang signifikan antara pemahaman agama dengan penerapan PHBS $(P$ value $0,000)$. Pengetahuan atau pemahaman seseorang adalah domain penting untuk membentuk perilakunya (Notoatmodjo, 2007).

\section{KESIMPULAN}

Hasil univariat menunjukkan bahwa sebagian besar responden memiliki PHBS yang kurang baik $(57,2 \%)$, pengetahuan yang baik $(50,7 \%)$, sikap yang baik $(60,1 \%)$, dan pemahaman Agama Islam yang baik (70,3\%). Hasil bivariat didapatkan bahwa tidak ada hubungan yang signifikan antara pengetahuan, sikap dan pemahaman agama Islam dengan PHBS ( $P$ value $>0,05)$. Saran dari penelitian ini, untuk FIKES UHAMKA, diharapkan adanya kegiatan yang berkelanjutan terkait dengan pelaksanaan PHBS agar mahasiswa tidak hanya sekedar mengetahui tetapi juga melakukan 
tindakan PHBS. Selain itu adanya dukungan melalui fasilitas penunjang PHBS juga sangat diperlukan. Untuk mahasiswa, Diharapkan mahasiswa dapat meningkatkan perilaku terkait PHBS sesuai dengan indikator PHBS di kampus dan berperan aktif. Untuk peneliti lain, Diharapkan dapat melakukan penelitian lebih lanjut dan komprehensif mengenai indikator PHBS secara khusus misalnya, aktivitas fisik, penimbangan berat badan dan pemberantasan jentik nyamuk.

Perilaku Hidup Bersih dan Sehat (PHBS) dapat diterapkan dimanapun tak terkecuali di lingkungan kampus. Lingkungan kampus merupakan tempat belajar bagi mahasiswa yang diharapkan dapat bersih dan ber-PHBS. Mahasiswa dapat menerapkan PHBS dalam kehidupan sehari-hari dan menjadi agen perubahan pada lingkungan sekitar. Apalagi di lingkungan kampus Muhammadiyah yang di dalamnya di tanamkan nilai-nilai Islam dalm praktik kehidupan sehari-hari.

\section{DAFTAR PUSTAKA}

Adliyani, Zaraz Obella Nur. (2015). Pengaruh Perilaku Individu terhadap Hidup Sehat. Majority Vol.4 No.7 Juni. Faculty of Medicine, Lampung University

Adri D.S. (2013). Perbandingan Pengetahuan, Sikap, dan Tindakan Murid Tentang Perilaku Hidup Bersih dan Sehat Di Sekolah Dasar Yang Memiliki dan Yang Tidak Memiliki Usaha Kesehatan Sekolah (UKS) Kecamatan Medan Baru Tahun 2013 [skripsi]. Sematera Utara: Fakultas Kesehatan Masyarakat. Universitas Sumatera Utara Bawole, B. B., Umboh, J. M., \& Sumampouw, J. O. (2018). Hubungan Antara Tingkat Pengetahuan Dan Sikap Dengan Tindakan Perilaku Hidup Bersih Dan Sehat Pada Murid Sekolah Dasar Gmim 9 Dan Sekolah Dasar Negeri Inpres Pinangunian Kota Bitung. Jurnal KESMAS, Vol. 7 No. 5.

Chandra, Fauzan, A., \& Aquarista, M. F. (2017). Hubungan Antara Pengetahuan Dan Sikap Dengan Perilaku Hidup Bersih Dan Sehat (Phbs) Pada Siswa Sekolah Dasar (SD) Di Kecamatan Cirebon Tahun 2016. JKMK Jurnal Kesehatan Masyarakat Khatulistiwa, 201-205.

Dinas Kesehatan DKI Jakarta. (2018). Profil Kesehatan Provinsi DKI Jakarta tahun
2017. Dinkes DKI Jakarta. https://dinkes.jakarta.go.id/profilkesehatan-dki-jakarta/.

Green L.W., \& Kreuter M.W. (2005). Health Program Planning: an Educational and Ecological Approach. 4th ed. New York: McGrow Hill

Haerani, F. N. (2011). Hubungan Antara Pengetahuan Agama Dan Sikap Terhadap Penerapan Phbs Tatanan Sekolah Di Smu Negeri 1 Riau Ale Kabupaten Bulukumba Tahun 2011. Universitas Islam Negeri Alauddin Makassar.

Muliadi, Irma Sari. (2015). Pengetahuan, Sikap dan Perilaku Hidup Bersih dan Sehat Pada Mahasiswa FKIK UIN Syarifhidatullah Jakarta. Laporan Penelitian

Notoatmodjo, S. (2007). Pendidikan dan Ilmu Perilaku Jakarta: PT Rineka Cipta

Notoatmodjo, Soekidjo. 2012. Promosi kesehatan dan Perilaku Kesehatan. Jakarta: Rineka Cipta

Kemenkes RI. 2011. PEMENKES RI. No.2269/MENKES/PER/XI/2011.

Pedoman Pembinaan Perilaku Hidup Bersih dan Sehat (PHBS). KEMNKES RI

Kementerian Kesehatan Republik Indonesia. (2013). Riset Kesehatan Dasar. Retrieved from http://labdata.litbang.depkes.go.id/risetbadan-litbangkes/menu-riskesnas/menuriskesdas/374-rkd-2013

Rohman, Bagus Nur. (2017). Pengaruh Pemahaman Keagamaan Terhadap Kebersihan Santri Pondok Pesantren Fadlun Minalloh Wonokromo Pleret Bantul. Skripsi UIN Syarif Hidayatullah Jakarta.

Santoso, A., \& Tiwi, S. N. (2019). Hubungan Antara Pengetahuan Agama Terhadap Perilaku Hidup Bersih Dan Sehat (PHBS) Pada Siswa Di Smp Negeri 2 Balaraja Tahun 2019. Jurnal Sosial Sains, 1-12.

Seni, S.S, Mariana, D.C.L, Ribka, L. (2010). Sikap Terhadap Perilaku Hidup Bersih dan Sehat Pada Mahasiswa STIKES Citra Husada Mandiri Kupang Tahun 2010. Kupang: MKM Vol. 05 No. 1. 01 Desember 2010 
Sumantri, Arif. (2015). Kesehatan

Lingkungan. Jakarta: Kencana Prenada Media Group 